Kevser Herdem 1

PhD Student, İnönü University, Faculty of Education

Department of Mathematics and Science Education

Malatya, Turkey

\section{Ibrahim Ünal²}

Prof. Dr., Inonu University, Faculty of Education

Department of Mathematics and Science Education

Malatya, Turkey
Original scientific paper

UDC: 37.013 .75

DOI: $10.5937 /$ IstrPed2002108H

\title{
DEVELOPMENT OF THE TENDENCY SCALE FOR SCIENTIFIC VALUES: A VALIDITY AND RELIABILITY STUDY
}

\begin{abstract}
Being a significant dimension in affective behavior education, values are guiding concepts for explaining the cognitive and social structures. In the process of value acquisition, the tendency of individuals for the value being targeted for acquisition bears a great significance. In the present study, the main aim is to develop an assessment instrument that can determine the tendency levels for the scientific values among students. In this process, the related literature was reviewed and an item pool was established. The item pool was presented to the expert opinion and following the necessary revisions, it was applied to the sample. The sample consisted of 268 secondary school students. In order to determine the validity of the scale, exploratory and confirmatory factor analysis was conducted. As a result of the validity analyses, a 4-factor structure consisting of 27 items was obtained and each factor was respectively named as the following in accordance with theoretical framework; "Curiosity", "Creativity," "Criticism", and "Inquisitiveness". The Cronbach's Alpha internal consistency coefficient, corrected item correlations, and the stability levels were calculated in order to determine the reliability of the scale. As a result of the study, it was found that the Tendency Scale for Scientific Values consisting of 4 factors and 27 items was a valid and reliable tool that can be used for determining the level of tendency for scientific values.
\end{abstract}

Keywords: Scientific values, scale development, validity and reliability.

\section{INTRODUCTION}

Values, can be defined as general principles guiding the behaviors, are the standards allow us to judge and categorize the actions. The concept of value that was introduced by Znaniecki for the first time is the main component of the cognitive constructions established in evaluating the community and individuals (Kucuradi, 2010). Therefore, at the present time when the technology is rapidly developing, the system of values of individuals influences the

\footnotetext{
${ }^{1}$ kevserherdem@gmail.com

2ibrahim.unal@inonu.edu.tr
} 
degree of scientific thinking, willingness to change, and adopting any innovation (Hurt, Joseph \& Cook, 1977).

According to Allchin (1999), science and values intersect in three points: the first is the epistemological values guiding the scientific studies, the second is the universal values teaching how to organize the cultural values, and the third is the level of influencing the value system of communities by scientific discoveries. According to Bayet (2010), a good scientific education is independent from values because being a scientist and examining the events in a scientific manner naturally leads our personal traits to a moral basis. People gain some moral values from the characteristics of science such as acting objectively, being critical, teaching to work with group, not being dogmatic, failing to generalize quickly, and seeking justifications for what is already accepted. According to Kucuradi (2010), the essence of science has universal values going beyond discriminating based on religion, language, gender, etc., as well as providing us to meet under the ideal of humanity. In the value classification made by Spanger (1928), for the first time, the concept of scientific values was given place. Spanger separated the concept of values into six groups; aesthetics, theoretical (scientific), economic, political, social and religious values. In the classification made by Spanger, scientific values are the values considered important by individuals regarding reality, knowledge, justification and critical thinking. A person having scientific values is the one who is experimental, critical, prioritizing observation, with a developed sense of curiosity, innovative, and rationalist. (Allport, Vernon \& Linzdey, 1960).

Akbas (2004) grouped values as the traditional values, democratic values, work-job values, scientific values, and the fundamental values. The values under scientific values involved being inquisitive, creative, curious, scientific, and critical.

It is seen that under the scientific values, emphasis was made in both value classifications on the values of Curiosity, Inquisitiveness, Creativity, and Being Critical. Moreover, in the value classification made by Schwart, the values of creativity and curiosity were defined in the value group of Self-Orientation (Ros, Schwartz \& Surkiss, 1999).

Curiosity; can be defined as the desire to notice, reveal and explore the new, difficult and ambiguous events (Kashdan et al., 2009). The concept of curiosity is explained by Piaget as a requirement for knowledge to increase, by Freud as the thirst for knowledge, by Hebb as a natural tendency of the organism for the cognitive processes, and by Maslow as a significant component in personal development (Reio, 1997). According to Thomas (2014), curiosity is the most significant element that provides intrinsic motivation of productive individuals. A curious learner likes complexities, is open to new experiences, is sensitive to differences, and has the abilities to determine assumptions and produce antithesis (Kashdan et al., 2009).

The concept of Creativity can be generally defined as developing different solutions for solving a particular problem and establishing a new relationship by considering the organizational network between the events (Wallach \& Kogan, 1965). Creative individuals are sensitive toward lack of knowledge and disharmony, have a high potential to develop many associations about a topic and open to innovations (Daniel, 1997).

Criticism is a reconstruction process for the results reached through cognitive inquiry and indepth consideration (McKnown, 1997). An individual thinking critically has the characteristics of seeking certainty in an occasion as much as possible, taking or changing a position based on sufficient evidence, being non-biased, and being able to think in depth (Ennis, 1989). 
Inquisitiveness can be defined as a whole of processes that target the unknown and aim to solve problems. An inquisitive individual not only has the values of being honesty, being nonbiased, and having social responsibilities, but they also work devotedly, pay attention to the consistency of the data obtained, and have a planned personality (Aydin, 2009).

When examining the literature, it was observed that studies on determining on creativity, curiosity, critical thinking, attitudes towards researches, and research skills have been conducted (Cikrikci, 1996; Ennis, 1989; Elena \& Papanastasiou, 2005; Kashdan et al., 2009; Walker, 2010). The concept of scientific values was involved in a limited number of studies. In the study by Allport, Vernon, and Linzdey (1960), the value classification of Spanger was converted into a scale and applied to a sample group consisting of various occupational groups and university students. In conclusion, it was obtained that artists received the highest score from aesthetic values; whereas, medical students had the highest score from the scientific values, religious clergymen received the highest score from religious and social values, and business administration students had the highest score from the economic values. On the other hand, Akbas (2004) developed a scale based on the value classification, applied it to primary school students, and consequently concluded that gender and socioeconomic level were effective on levels of students for reaching the value groups classified under title of the scientific values.

Training individuals internalizing scientific values is the first step to the transformation into information society because the dynamic of scientific thinking based on assumption production and constant inquiry has the power to transform the social perception. From this point view, scientific values are not just an educational attainment, but they also have an extremely significant effect over the social welfare. In the process of value acquisition, the tendencies of individuals toward the targeted values have a special importance. The level of such tendency affect the behavioral ways, attitudes, intrinsic motivations, and social aspect of individuals. From this perspective, it seems important to determine the tendency level for scientific values among students. The aim of the present study is to develop an assessment instrument by taking the aforementioned value classifications as a criterion.

\section{METHOD}

\section{Sample Group}

The sample group of the study consisted of a total of 268 students, who were studying in the $7^{\text {th }}$ and $8^{\text {th }}$ grades of secondary schools. Table 1 shows the distribution of students based on grade level and gender.

Table 1. Distribution of the Sample Group Based on Grade Level and Gender

\begin{tabular}{cccc}
\hline Grade Level & Female & Male & Total \\
\hline 7 & 42 & 68 & 110 \\
\hline 8 & 70 & 88 & 158 \\
\hline
\end{tabular}

\section{Scale Development Process}

The related literature was reviewed for the purpose of determining the items to take place in the Tendency Scale for Scientific Values (TSSV) (Cikrikci, 1996; Ennis, 1989; Kashdan et al., 
2009; Akbas, 2004). As a result of the evaluations, an item pool consisting of a total of 40 items including 12 negative items and 28 positive items was established. Five-point options were placed in front of items in order to determine the tendency levels for characteristics expressed in them. These options were arranged and scored as: Always (5) Usually (4), Sometimes (3), Rarely (2), and Never (1).

\section{RESULTS}

The processes and results carried out within the framework of validity and reliability analyses of the scale are presented below.

\section{Results Related to Content and Appearance Validity}

Content validity is an indicator for whether or not items of the scale is sufficient qualitatively and quantitatively to measure the desired behavior. Applying to an expert opinion is one of prior prediction studies for the content validity. The draft form consisting of 40 items, which was prepared upon literature review, was sent to seven experts to assess it in terms of criteria of being fit to student levels, level of serving the aim, and comprehensibility. Davis Technique was applied for the purpose of evaluating on the expert opinions in the content validity study. The Davis technique rates the expert opinions in a four-point scale as (a) "Fit", (b)" Item should be reviewed slightly", (c) "Item should be reviewed seriously", (d) "Not fit". In this technique, the number of experts choosing the options (a) and (b) is divided into the total number of experts to obtain the content validity index (CVI) related to the item and this value is expected to be higher than 0.80 (Davis, 1992).

Table 2. CVI Values Obtained as a Result of Expert Opinions

\begin{tabular}{|c|c|c|c|}
\hline Item number & CVI & Item number & CVI \\
\hline 1 & 1 & 21 & 1 \\
\hline 2 & 0.86 & 22 & 1 \\
\hline 3 & 1 & 23 & 0.86 \\
\hline 4 & 1 & $24^{*}$ & 0.70 \\
\hline 5 & 1 & 25 & 1 \\
\hline 6 & 1 & 26 & 1 \\
\hline 7 & 1 & 27 & 1 \\
\hline $8^{*}$ & 0.57 & $28 *$ & 0.57 \\
\hline 9 & 1 & 29 & 1 \\
\hline 10 & 1 & 30 & 1 \\
\hline 11 & 1 & $31^{*}$ & 0.43 \\
\hline 12 & 1 & 32 & 1 \\
\hline 13 & 0.86 & 33 & 1 \\
\hline 14 & 1 & 34 & 1 \\
\hline 15 & 0.86 & 35 & 1 \\
\hline $16^{*}$ & 0.57 & 36 & 1 \\
\hline 17 & 1 & 37 & 1 \\
\hline 18 & 1 & 38 & 0.85 \\
\hline 19 & 1 & 39 & 1 \\
\hline 20 & 1 & 40 & 1 \\
\hline
\end{tabular}

*Items omitted as a result of the content validity 
As a result of the feedback coming from the experts, agreement was reached on 35 of 40 items. Some of the items were corrected and it was concluded that the scale was able to measure the tendency of students for scientific values.

\section{Results Related to Construct Validity}

In the process of developing a standardized assessment instrument, one of the most significant characteristics related to the validity of the scores obtained from the scale is the construct validity. Factor analysis, the most frequently used method in scale development studies in social sciences, offers a road map to the researcher for statistical solutions (Buyukozturk, 2002). Exploratory factor analysis is an inquiry operation on whether or not the items collected under a certain factor are indicators of the theoretical structure measured. In this study, the construct validity of TSSV was tested by exploratory factor analysis.

Exploratory Factor Analysis (EFA): When examining the literature, one of the methods used within the scope of exploratory factor analysis is the Principal Components Analysis (Cokluk, Sekercioglu and Buyukozturk, 2016:187). Before the TSSV is subjected to the principal components analysis, the eligibility of the current data for analysis was tested. Correlation between the variables, being free of extreme and missing values and the normal distribution of the data set, sample size, and sampling adequacy (KMO and Bartlett's test of Sphericity) are the criteria to be tested before initiating the factor analysis. In the raw form, the data set consisting of 268 people was applied with the Bartlett's test of Sphericity and its skewness, and kurtosis values were analyzed. The items 13, 19, and 27 that showed qualities of high negative skewness (Skewness ${ }_{(13)}=-1.840 ; \quad$ Skewness $_{(19)}=-1.907 ; \quad$ Skewness $_{(27)}=-2.730$ ) and kurtosis (Kurtosis $(13)=3.062$; $\operatorname{Kurtosis}_{(19)}=4.012$; $\operatorname{Kurtosis}_{(27)}=3.462$ ) were omitted from the analysis. When the results of Bartlett's test of Sphericity $\left(X_{2}=2160.557 ; s d=351 ; p=.000\right)$ were examined, it was accepted that the data came from a multivariate normal distribution. In addition, the Kaiser-Moyer-Olkin (KMO) test was applied and as a result of the analysis (KMO value $=.811$ ) it was concluded that the sample size was in a "good" level in order to carry out the factor analysis (Çokluk, Şekercioğlu, and Büyüköztürk, 2016, p.207).

While principal components analysis was chosen as factorization method for the purpose of revealing the factor design of the Tendency Scale for Scientific Values, maximum variation (marimax) was chosen as rotation method. In the initial analysis, it was observed that there were a total of 7 factors, whose eigenvalues were above 1 . Their contribution to the total variance was $71.450 \%$. When evaluating these factors within the framework of the significance of the contribution to total variance by examining the total variance table and scree plot (Figure 1), it was observed that while the four factors had a significant contribution to variance, the contribution after the 5 th component was both little and approximately the same. 


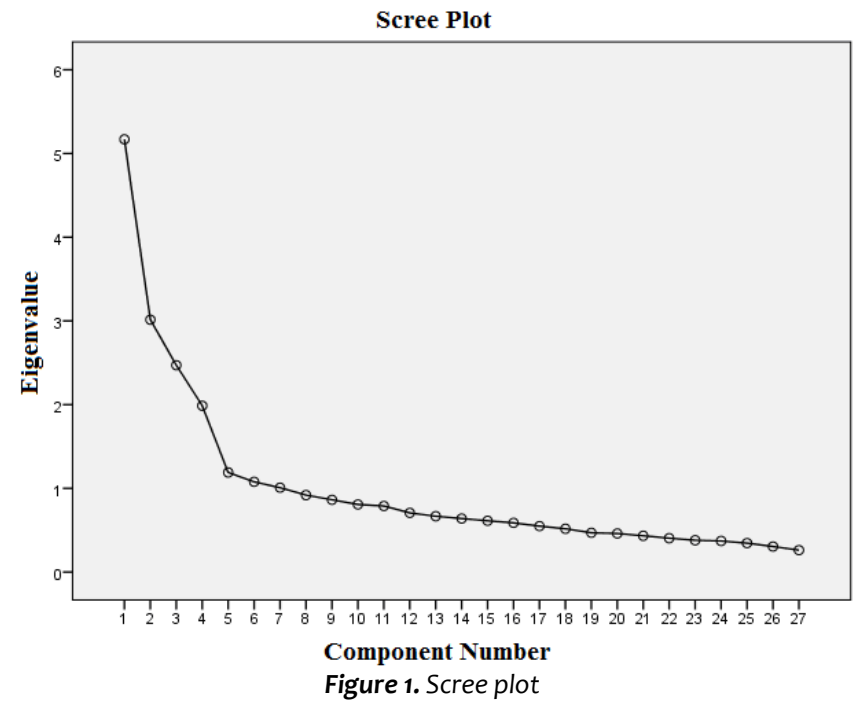

Table 3 shows the contribution made to the total variance by the factors in the analysis repeated for the four factors as well as the eigenvalues.

Table 3. Eigenvalues and the Explained Variance Rates

\begin{tabular}{ccc} 
Factors & Eigenvalues & Explained variance rates \\
\hline $\mathbf{1}$ & 7.169 & 21.145 \\
\hline $\mathbf{2}$ & 5.014 & 15.164 \\
\hline $\mathbf{3}$ & 3.471 & 11.153 \\
\hline $\mathbf{4}$ & 2.387 & 9.359 \\
\hline Total & 12.041 & $* 56.821$ \\
\hline *It is sufficient that the explained variance rates in terms of behavioral science is \% 40 (Can, 2014).
\end{tabular}

For the determination of the items to be included in the scale, the load values of items be at least 0.32 . As a result of evaluations, five items were removed from the scale because their factor loadings were below 0.32; they take place in multiple factor. It was found the scale consisting of 4 factors and 27 items. The factor loadings and covariance variances of the items were present in the Table 4.

Table 4. Factor Load Values and Covariance Variances of the Items

\begin{tabular}{ccc}
\hline Items & Covariance variances & Factor load values \\
\hline$M 1$ & 0.629 & \\
\hline$M 2$ & 0.342 & 0.744 \\
\hline$M 3$ & 0.493 & 0.522 \\
\hline$M 4$ & 0.392 & 0.696 \\
\hline$M 5$ & 0.397 & 0.514 \\
\hline$M 6$ & 0.596 & 0.574 \\
\hline$M 7$ & 0.591 & 0.766 \\
\hline$M 8$ & 0.608 & 0.671 \\
\hline & Factor 2(Criticism) & 0.746 \\
\hline
\end{tabular}




\begin{tabular}{|c|c|c|}
\hline M9 & 0.589 & 0.720 \\
\hline M10 & 0.457 & 0.663 \\
\hline M11 & 0.470 & 0.625 \\
\hline M12 & 0.351 & 0.581 \\
\hline M13 & 0.461 & 0.664 \\
\hline M14 & 0.517 & 0.658 \\
\hline M15 & 0.539 & 0.676 \\
\hline M16 & 0.361 & 0.508 \\
\hline \multicolumn{3}{|c|}{ Factor 3 (Inquisitiveness) } \\
\hline M17 & 0.571 & 0.722 \\
\hline M18 & 0.346 & 0.675 \\
\hline M19 & 0.473 & 0.661 \\
\hline $\mathrm{M} 2 \mathrm{O}$ & 0.486 & 0.603 \\
\hline M21 & 0.476 & 0.688 \\
\hline $\mathrm{M} 22$ & 0.531 & 0.705 \\
\hline \multicolumn{3}{|c|}{ Factor 4 (Creativity) } \\
\hline $\mathrm{M} 23$ & 0.435 & 0.556 \\
\hline M24 & 0.504 & 0.652 \\
\hline M25 & 0.436 & 0.534 \\
\hline $\mathrm{M} 26$ & 0.438 & 0.626 \\
\hline $\mathrm{M} 27$ & 0.455 & 0.600 \\
\hline
\end{tabular}

Confirmatory Factor Analysis (CFA): Confirmatory factor analysis was carried out in order to confirm the factor structure of the scale that was determined to be comprised of 4 factors as a result of the exploratory factor analysis. For this purpose, the scale with 27 items was applied to a different sample group including 200 people. Figure 2 shows the factorial model of the scale and the $t$ value pertaining to its factor-item correlation.

The goodness of fit values obtained from the confirmatory factor analysis were present in the Table 5 .

Table 5. Goodness of Fit Values Obtained as a Result of the Confirmatory Factor Analysis

\begin{tabular}{cccc}
\hline Goodness of fit values & Perfect & Acceptable & Values \\
\hline $\mathbf{p}^{*}$ & $>.01$ or .05 & $<.01$ or .05 & $.000(\mathrm{~K})$ \\
\hline $\mathbf{X}^{2} / \mathbf{s d}$ & $\leq 2$ & $2-5$ & $472.01 / 269=1.75$ \\
\hline RMSEA & $\leq .05$ & $\leq .08$ & .062 \\
\hline RMR & $\leq .05$ & $\leq .08$ & .044 \\
\hline GIF & $\geq .95$ & $\geq .90$ & .90 \\
\hline AGFI & $\geq .95$ & $\geq .90$ & .85 \\
\hline CFI & $\geq .95$ & $\geq .90$ & .99 \\
\hline NFI & $\geq .95$ & $\geq .90$ & .98 \\
\hline NNFI & $\geq .95$ & $\geq .90$ & .99 \\
\hline IFI & $\geq .95$ & $\geq .90$ & .99
\end{tabular}

* $p$ value is significant. However, it is seen that $p$ value is significant in many confirmatory factor analyses because of having a large sample. Therefore, alternative fit indices should be examined (Çokluk, Şekercioğlu and Büyüköztürk, 2016). 
When the observed values of the model, it was seen that IFI, NNFI, NFI, CFI, and RMR showed perfect fit; whereas, RMSEA showed an acceptable fit. In other words, this model indicated the confirmation of the factors by the data.

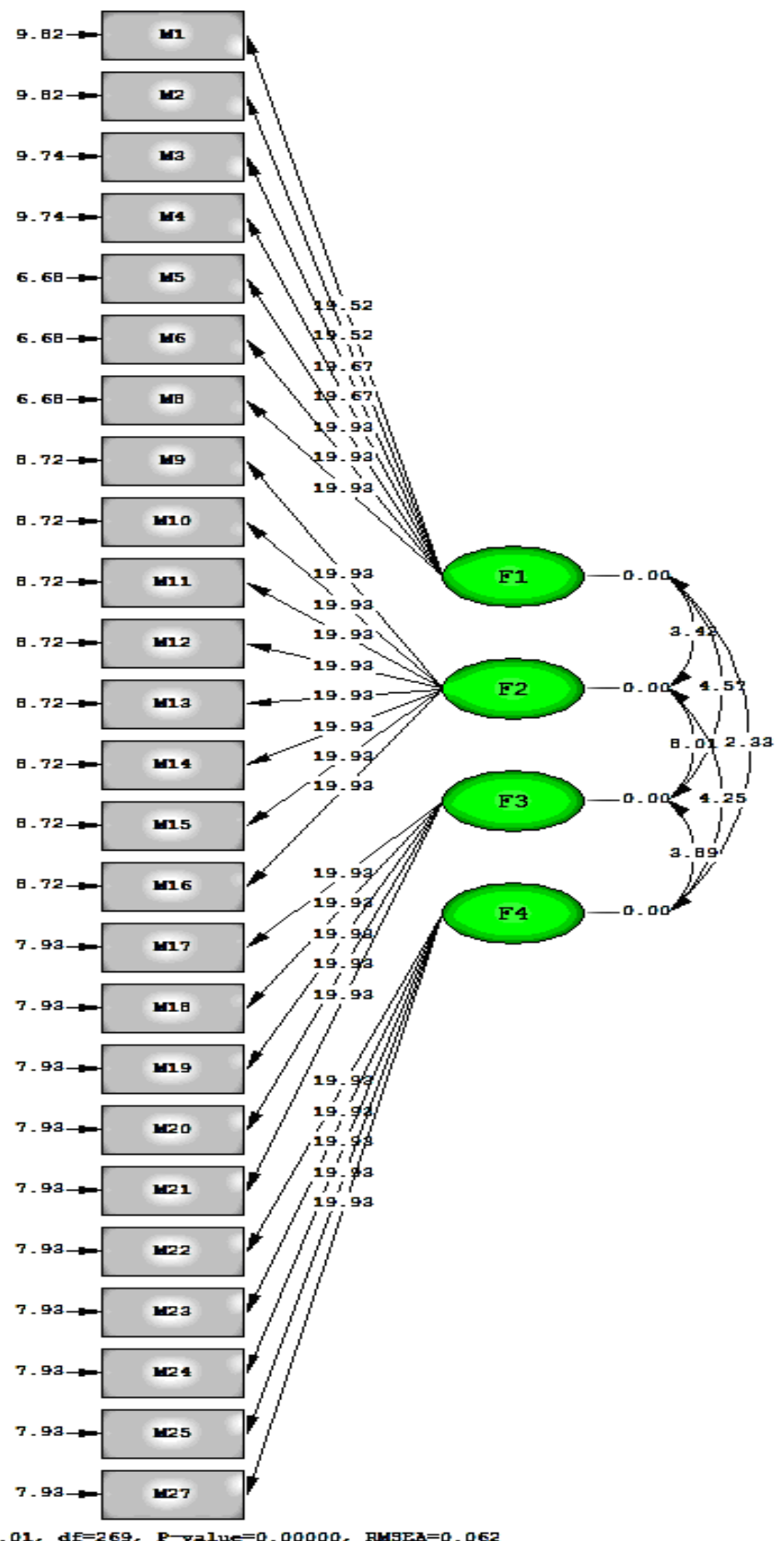

Figure 2. Factor analysis connection diagram for the scale ( $t$-values) 


\section{Reliability}

In order to calculate the reliability of TSSV in this study, internal consistency and stability analyses were carried out. The obtained results are present in the Table 6.

Table 6. Cronbach's Alpha Internal Consistency Coefficient and the Corrected Item Total Correlations

\section{Items Corrected item total correlations (268)}

\begin{tabular}{|c|c|}
\hline \multicolumn{2}{|c|}{ Factor 1 (Curiosity) } \\
\hline M1 & 0.782 \\
\hline $\mathrm{M} 2$ & 0.836 \\
\hline$M_{3}$ & 0.696 \\
\hline M4 & 0.517 \\
\hline M5 & 0.667 \\
\hline M6 & 0.564 \\
\hline M7 & 0.378 \\
\hline M8 & 0.410 \\
\hline \multicolumn{2}{|c|}{ Cronbach's alpha $=0.811$} \\
\hline \multicolumn{2}{|c|}{ Factor 2 (Criticism) } \\
\hline M9 & 0.662 \\
\hline M10 & 0.462 \\
\hline M11 & 0.441 \\
\hline M12 & 0.599 \\
\hline M13 & 0.392 \\
\hline M14 & 0.359 \\
\hline M15 & 0.406 \\
\hline M16 & 0.346 \\
\hline M17 & 0.456 \\
\hline \multicolumn{2}{|c|}{ Cronbach's alpha=0.809 } \\
\hline \multicolumn{2}{|c|}{ Factor 3 (Inquisitiveness) } \\
\hline M18 & 0.589 \\
\hline M19 & 0.435 \\
\hline $\mathrm{M} 2 \mathrm{O}$ & 0.500 \\
\hline M21 & 0.491 \\
\hline $\mathrm{M} 22$ & 0.456 \\
\hline \multicolumn{2}{|c|}{ Cronbach's alpha=0.722 } \\
\hline \multicolumn{2}{|c|}{ Factor 4 (Creativity) } \\
\hline $\mathrm{M} 23$ & 0.537 \\
\hline M24 & 0.478 \\
\hline $\mathrm{M} 25$ & 0.409 \\
\hline $\mathrm{M} 26$ & 0.462 \\
\hline M27 & 0.565 \\
\hline \multicolumn{2}{|c|}{ Cronbach's alpha=0.792 } \\
\hline
\end{tabular}

The Cronbach's alpha values of reliability of the data obtained from the scale in terms of internal consistency were calculated respectively 0.811 for factor $1,0.809$ for factor 2, 0.722 for factor 3 , and 0.792 for factor 4 . Accordingly, it can be asserted that the internal consistency coefficient for the factors of the scale was high. Thus, the Cronbach's alpha reliability coefficient of 0.70 and higher is regarded as an indicator of a scale's reliability (Can, 2014). 
The corrected item-total correlations calculated for the items located in each factor of the scale vary between 0.378 and 0.836 . The corrected item total correlations of $>0.20$ shows that each item serve significantly for the purpose of the related factor (Can, 2014).

The stability level of the scale was calculated by using test-retest method. A different sample group of 95 students was applied with its final form having 27 items with four-week interval. Table 7 shows the obtained data.

Table 7. Test-Retest Results of the Factors of the Scale

\begin{tabular}{|c|c|c|c|c|c|}
\hline \multirow{6}{*}{ 芯 $\frac{\frac{c}{0}}{\frac{0}{0}}$} & \multicolumn{5}{|c|}{ Second application } \\
\hline & & F1 & F2 & $F_{3}$ & F4 \\
\hline & F1 & .917 & & & \\
\hline & F2 & & .908 & & \\
\hline & $F_{3}$ & & & .872 & \\
\hline & $\mathrm{F}_{4}$ & & & & .897 \\
\hline
\end{tabular}

It is seen from Table 7 that the correlation coefficients obtained by test-retest method for the factors of the scale varied between 0.872 and 0.917 , and each correlation was significant and positive $(p<0.01)$.

\section{CONCLUSIONS}

In this study, a scale was developed for the purpose of determining the tendencies for scientific values. When examining the results of the analyses, it can be asserted that TSSV is a valid and reliable assessment instrument. Because number of studies measuring the scientific values is limited in the literature, it is hoped that the scale would contribute to the studies for the science education and affective domain.

There are some limitations in the study. The primary limitation is that the study was conducted only on secondary school students. The fact that the students were selected only from one region may not offer data for regional differences. The study can be repeated with a sample group including students in the same level of education, who are selected from different regions.

Additional studies may be conducted to increase the construct validity of the scale and to test the criteria validity. The effect of individual differences, brought by students from different age groups to the learning setting, on tendencies for scientific values, as well as relationship between perspectives on technological advances and levels of reaching scientific values can be examined.

\section{REFERENCES}

Akbas, O. (2004). Evaluation of the Degree of Reaching of Affective Goals at the Elementary Level in Turkish National Education System. Unpublished Doctoral Thesis, Gazi University, Ankara.

Allchin, D. (1999). Values in science: An educational perspective, Science \& Education, 8(1), 1-12. Allport, G. W., Vernon, P. E. \& Lindzey, G. (1960). A Study of Values. Boston: Houghton-Mifflin. Aydin, E. (2009). Arastirma ve Yayin Etiginde Arastirmacinin Degerler Sistemi [Researher's Values System in Research and Publication Ethics]. Periodical Publishing in Health Sciences-7. National Symposium, 20 October 2009, Ankara. 
Bayet, A. (2010). Bilim Ahlaki [Ethics of Science]. Mavicati Publication, Ankara.

Buyukozturk, S. (2002). Sosyal Bilimler icin Veri Analizi El Kitabi [Data Analysis Handbook for Social Sciences]. Ankara: Pegem Akademi Publication.

Can, A. (2014). SPSS ile Bilimsel Arastirma Surecinde Nicel Veri Analizi [Quantitative Data Analysis in Scientific Research Process with SPSS]. Ankara: Pegem Akademi Publication.

Cikrikci, N. (1996). Elestirel Dusunme: Bir Olcme Araci ve Bir Arastirma [Critical Thinking: A Measurement Tool and A Research], III. National Psychological Counseling and Guidance Congress, Adana.

Cokluk, O., Sekercioglu, G. \& Buyukozturk, S. (2016). Sosyal Bilimler icin Cok Degiskenli Istatistik, SPSS ve LISREL Uygulamalari [Multivariate Statistics, SPSS and LISREL Applications for Social Sciences]. Ankara: Pegem Akademi Publication.

Daniel, M. H. (1997). Intelligence testing: Status and trends, American Psychologist, 52(10), 1038-1045. http://dx.doi.org/10.1037/0003-066X.52.10.1038.

Davis, L. L. (1992). Instrument review: Getting the most from a panel of experts. Applied Nursing Research, 5, 194-197.

Elena, C. \& Papanastasiou, E. C. (2005). Factor structure of the attitudes toward research, scale, Statistics Education Research Journal, 4(1), 16-26.

Ennis, R. (1989). Critical thinking and subject specificity: Clarification and needed research, Educational Researcher, 3(18), 4-10.

Hurt, H. T., Joseph, K. \& Cook, C. D. (1977). Scales for the measurement of innovativeness, Human Communication Research, 4, 58-65.

Kashdan, T. B., Gallagher, M. W., Silvia, P. J., Winterstein, B. P., Breen, W. E., Terhar, D.T. \& Steger, M. F. (2009). The curiosity and exploration inventory-II: Development, factor structure, and psychometrics, Journal of Research in Personality, 43, 987-998.

Kucuradi, I. (2010). Insan ve Degerleri [Human and Values]. Publications of Turkish Philosophy Association, Ankara.

McKnown, K. (1997). Fostering Critical Thinking. A Research Paper to Air Command and Staff College, USA.

Reio, T. G. (1997). Effects of Curiosity on Socialization-Related Learning and Job Performance in Adults. Unpublished Doctoral Thesis, Virginia Polytechnic Institute and State University, USA.

Ros, M., Schwartz, S. H. \& Surkiss, S. (1999). Basic individual values, work values and the meaning of work, Applied Psychology: An International Review, 48(1), 49-71.

Thomas, A. (2014). Making Makers: Kids, Tools, and the Future of Innovation, O’Reilly Media Inc. Sebastopol.

Walker, D. A. (2010). A confirmatory factor analysis of the attitudes toward research scale, Multiple Linear Regression Viewpoints, 36(1), 247-302.

Wallach, M. A. \& Kogan, N. (1965). A new look at the creativity-intelligence distinction, Journal of Personality, 33, 348-369. doi: 10.1111/j.1467-6494.1965.tbo1391 


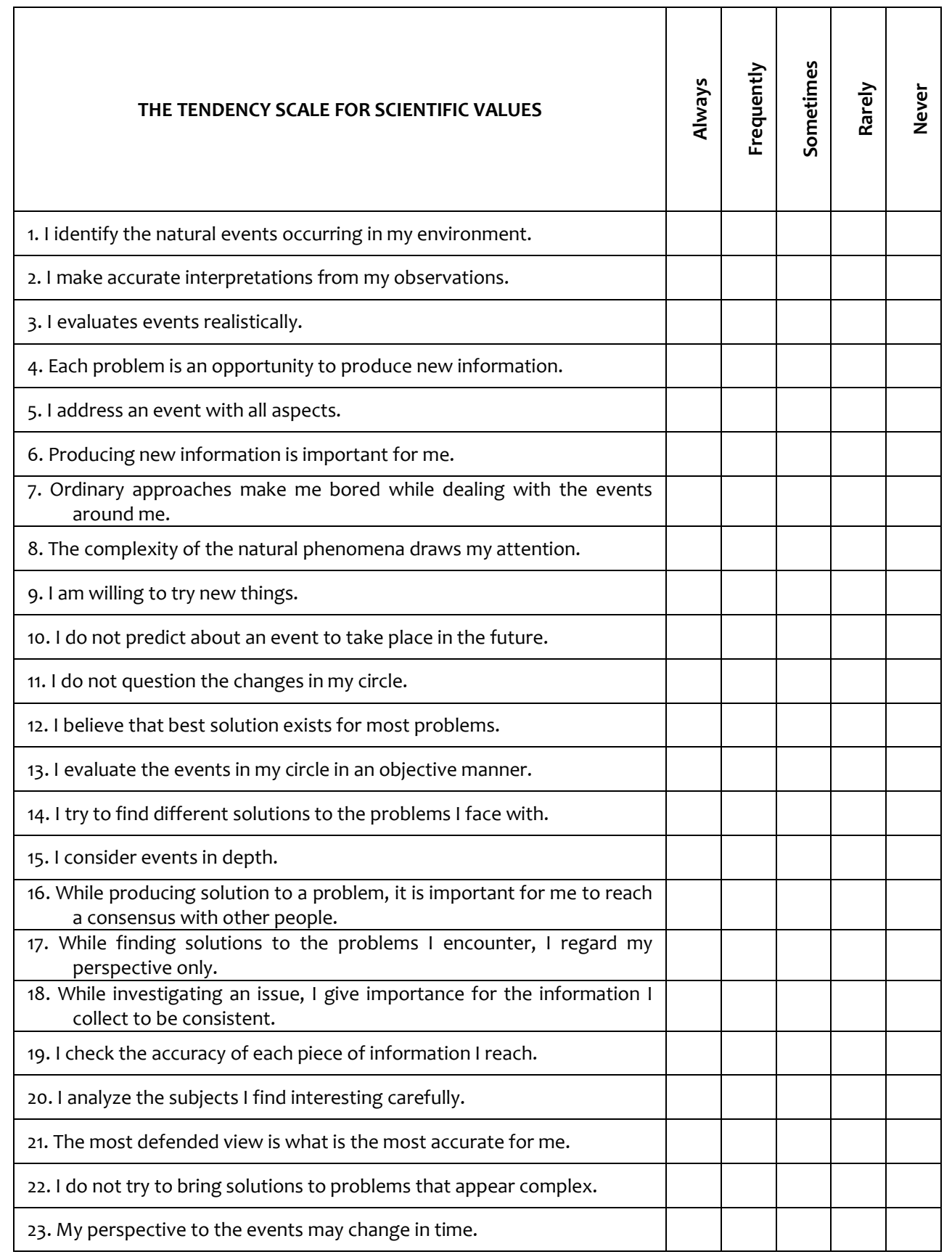




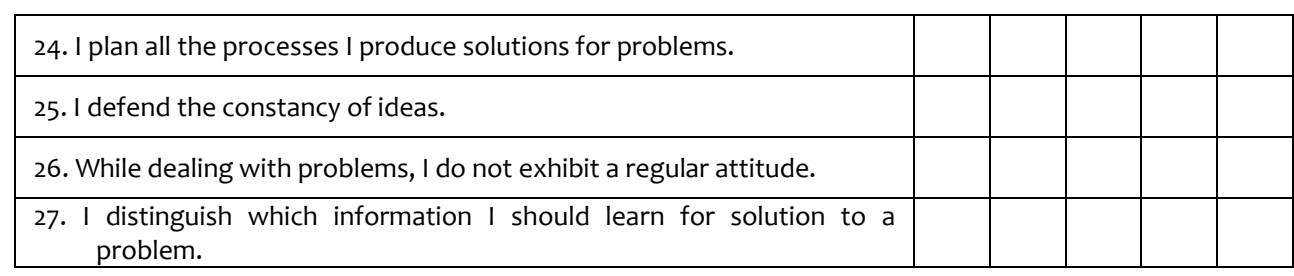

\section{Biographical notes:}

Kevser Herdem completed her bachelor's degree at the Dicle University Faculty of Education in 2011, master degree on science education at the Adiyaman University in 2016. She has been studying as PhD student at İönü University Faculty of Education since 2016. She works areas are science education, STEM education, values in science education.

Ibrahim Ünal completed his bachelor's degree at the FIrat University Faculty of Science in 1994, master degree on the near Earth space physics at Firat University in 1997 and PhD degree on the near Earth space physics at Firat University in 2003. He works areas are plasma physics, science education, astronomy education and physics education. He has been working as a professor at İnönü University Faculty of Education since 2018. 